\title{
Patently Obvious: The place for patents in information literacy in the sciences
}

\author{
Don MacMillan * \\ Mackinnie Library, University of Calgary, 2500 University Drive, NW, Calgary, Alberta, Canada T2N 1N4
}

Available online 30 August 2006

\begin{abstract}
Patents are an underutilized source of scientific information, particularly in the life and health sciences. Patents and patent applications usually contain the first disclosure of new technologies and processes and serve to link theory with practice, providing 'real world' examples of the application of scientific research. Increasingly, scientific discoveries are reported first in the patent literature, rather than in academic journals. To ensure that science students have the skills that match the information resources they will use as professionals, patent searching must become part of their information literacy instruction. This article will discuss how valuable the patent literature can be to students, and how to incorporate patent searching into library instruction. By way of illustration, a case study will document how students in one class, Biochemistry 561, were introduced to patents.

(C) 2006 Elsevier Inc. All rights reserved.
\end{abstract}

Keywords: Patents; Patent literature; Information literacy; Science

\section{Introduction}

While this article focuses on the place of patents in the Biological Sciences literature, much of what is discussed is applicable to librarians and instructors in Chemistry, Engineering and other science and technology-based areas. Scientific literature has traditionally relied on journals and conference proceedings as the primary sources of scholarly information.

* Fax: +1 4032826024.

E-mail address: macmilld@ucalgary.ca. 
Increasingly, faculty and their students in the Biological Sciences Department at the University of Calgary are expanding their knowledge base to include non-traditional, information-rich resources such as patents. Recent improvements in the availability and accessibility of patents worldwide, particularly the digitization of patents and patent applications and the introduction of more sophisticated search and retrieval tools via the Web, have introduced more users to this increasingly important source of primary and scholarly information. Teaching patent searching to students has become much easier as patent information has become more readily, and freely available via the Internet. The nature of patent information requires librarians to go beyond teaching students how to locate relevant information and to provide instruction in interpreting patent literature so that students can appreciate and make the most of these resources.

The University of Calgary Library in collaboration with the Department of Biological Sciences has had a long tradition of recognizing the need for introductory and advanced library instruction sessions for students in biological sciences courses. All first-year biology students and most second-year Biology majors are required to participate in course-related library instruction sessions where students are introduced to the scientific literature, key databases and the research skills required to retrieve, analyze and communicate scientific knowledge. Upper level students, particularly in biochemistry and microbiology, receive more extensive training and are introduced to more advanced searching techniques using a range of databases for their course-related projects, assignments and oral presentations. Students in several of these courses are also introduced to non-traditional sources of scientific information including patents. Biochemistry 561 is just one of these advanced courses and is the focus for this case study.

\section{The literature}

Along with articles and other academic publications, patents provide a public record of research and development activities for universities, corporations, government agencies and individual inventors. Approximately 700,000 patents are granted annually worldwide and two thirds of patent information is never disclosed or published elsewhere according the World Intellectual Property Organization (2002). Patent applications are also usually the first disclosure of a new technology or process (Kehoe \& Yu, 2001a,b). In addition, patents are an important indicator of scientific, corporate, and national innovation, $R \& D$ trends, industrial developments and corporate intelligence (Mogee, 1997). Patents are also an important economic barometer, as the world's economic powerhouses typically generate the highest number of patents. Many scientists and researchers apply for patent protection in disciplines such as biotechnology, biochemistry, microbiology as well as chemistry and engineering. Specific areas with a proliferation of patent activity in the biological sciences include genomics, biochemical techniques and methods, drugs, plant and animal biotechnology, and pharmacology. Much information in these fields may be published only in the patent literature or will appear there long before being published in traditional sources of biological literature such as peer-reviewed journals and conference proceedings (Church \& Carpenter, 2000). An increasing number of scientists in both the academic and corporate sectors are patenting their discoveries and processes, generating an expanding body of primary literature to complement the scholarly 
journal literature. Glanzel \& Meyer (2003) have expanded on this publishing pattern even further by concluding that a significant number of scientific papers cite patents, underlining the significant link between specific processes and instruments relevant to scientific research.

There has been comparatively little discussion in the library literature of the value of patents as a primary and scholarly source of scientific information and the reasons why students should be introduced to the patent literature, notable exceptions being Church \& Carpenter (2000) and Kawakami (1998). This body of scientific knowledge is usually not introduced to science students in library instruction sessions nor is it part of their traditional science education. There are several reasons for this: many instruction librarians may not be fully aware of the inherent value or content contained within patents (Church \& Carpenter, 2000), librarians may not be aware of how much easier patent searching has become in the last five years, and in many cases, librarians may feel unable to add a complex information source to an already crowded curriculum.

There has been discussion in the literature of using other, non-bibliographic databases such as the Bioinformatics databases offered by PubMed, and the Online Mendelian Inheritance in Man. Librarians will have to attain some fluency with these resources and expand their information literacy efforts to ensure that instruction remains relevant to users (Brown, 2005; Bowden \& DiBenedetto, 2001; Chiang, 2004). Bowden \& DiBenedetto (2001), further articulate that these freely available resources have a profound impact on how science is conducted. Interestingly, the need for instruction in the use of patents has been most clearly articulated outside library literature, in a document prepared by the SMEs Division of the World Intellectual Property Organization (2002), which states “...promoting greater awareness of the usefulness of patent literature and training on how to use patent databases should be perceived as important goals for universities...." This document and other 'external' sources including Crespi (2004) also emphasize the need for teaching students how to interpret patent literature.

\section{Why should patent searching become part of information literacy sessions?}

At our institution faculty requested the inclusion of patent searching in library instruction workshops, but that may not be the case elsewhere. Building a case for including patents may start with convincing teaching faculty of their importance. Many faculty requesting library instruction sessions hold patents and are fluent with their content and place in the scientific literature. For librarians, students, and researchers in the life sciences, it is not enough to be familiar with the search protocols for various patent databases; understanding and interpreting these often unfamiliar, jargon-filled resources are equally important skills to include in advanced information literacy sessions.

Patent searching serves a number of curricular goals. It provides students with access to very current information, and answers a common faculty complaint of slow academic publishing cycles. Patent applications are timely and can bring student to the very cutting edge of science. Patents inherently link theory and application, academia and the 'real world' and can be incorporated into assignments as starting points for discussions of how science affects society. Patents can also be used to teach the current history of science; where most books 
focus on early developments of scientific knowledge, tracing the patent activity around a scientific instrument or process can provide students with valuable insights about the accumulative nature of scientific discovery. Finally, it is increasingly likely that students in the life sciences will find work outside of academia. Knowledge of patent databases and searching will be a valuable skill for them to take to the non-academic research world. Those students continuing an academic career will also likely be involved in knowledge generation leading to patents as well as or even instead of articles in journals. As future developers of patented processes, organisms or materials, familiarity with the patent system will be a benefit to their professional and academic careers.

\section{What do students need to know about patents?}

First, students need to know what patents are and how they fit with the rest of scientific literature. According to the McGill University Office of Technology Transfer (2005) "A patent is a right granted by a national government, upon application and in exchange for a complete disclosure of an invention." Upon payment of annual fees, patents generally have a life of 17 to 20 years, depending on the jurisdiction. In Canada, patents have a lifetime of 20 years from the date of filing. As patents can be used for scientific, legal and business purposes they are an ideal source for biotechnology information as students must be cognizant of these diverse perspectives. Many students are only vaguely aware of the existence of patents and very few know that they can cover processes and organisms as well as more conventional inventions. In some cases, students may have been using the patent literature without realizing it, accessing patents through databases such as SciFinder Scholar (Chemical Abstracts) or PubMed; for others, searching patents may take them out of their comfort zone of journal databases and library catalogues. Students need to recognize patents as authoritative and up-to-date sources.

Second, students need to learn how to read and interpret patents and that can include surmounting a language barrier. As noted by Crespi (2004) "a scientific paper, written by the scientist and for the scientist, is designed primarily to record scientific knowledge. A patent specification, by contrast, is written by an inventor for the instruction of those wishing to make a practical application of the inventor's finding." In theory, a patent must be clear enough to guide a skilled person to carry out a method or process or to re-create the invention. The language used to do that though, is quite often a blend of scientific jargon and legalese, in a format unfamiliar to most students. It is well worth taking the time to explain the structure of patents and applications, to note how they differ from scholarly articles, and to allay students' initial misgivings about the occasional lack of clarity in patent documents. An outline of the key components of a typical United States patent used to help biotechnology students identify the key data fields within a patent is available in Appendix A.

A United States patent can have up to 32 searchable data fields that are similar to bibliographic fields. The primary data fields that Instruction Librarians and students need to know include: the patent number; title; abstract; inventor or assignee; the classification number (s); claims, where the specifics of the innovation are laid out; the background, which provides useful information on the development of the invention; the references, both to the literature 
and to other patents; and the illustrations or images. The images and illustrations are often the most useful parts of a patent or patent application and students should be encouraged to read the patent with the illustrations or images close at hand.

Of course, students also need to learn how to search for patents using both the uncontrolled vocabulary of the abstracts and full text and the controlled chaos of the classification system. As many other forms of literature are now citing patents by number, explaining how to access specific documents is also useful. Searching patents is very similar to searching the scientific literature. Once a topic has been selected, initial screening of preliminary patent searches generates a list of possible new keywords, classification numbers or descriptors that can be used to further refine subsequent searches. While keyword searching may yield relevant results, where patents contain information about a new technology or processes, existing terminology may not accurately describe a new invention, so it is important to teach students how to search by class and sub-class numbers as well. It is also helpful to provide students with an example of how to cite patents as most student documentation guides omit this type of source.

Finally, and perhaps only in more advanced classes, students should be encouraged to explore what else patents can tell them about their discipline-where are the new discoveries being made, how fast is the field changing, what instruments are being used in the development of new processes, and in some cases the valuable lessons of how old some technologies really are. As with journal articles, citation analysis can provide information on high-impact discoveries, and how they influence further work.

\section{Where to look for patent information}

While patent agencies worldwide have tried to provide users with convenient access to patent information, many early patent search tools were very cumbersome to use and possessed limited searching and retrieval capabilities. Specialized proprietary systems such as Questel-Orbit, Dialog and Lexis-Nexis have always provided comprehensive patent and intellectual property coverage and sophisticated searching features for a fee, but most users did not possess the requisite searching skills or training, nor have convenient access to these systems (See Appendix B). Since the inception of the World Wide Web, many patent-granting agencies have digitized much of their patent information, including the corresponding images, and enhanced searching capabilities to the point where most users are able to conduct basic to sophisticated searches for free. Several bibliographic databases provide selective keyword or subject access to patent information, including SciFinder Scholar and Web of Science. However, students in Biochemistry 561 and other biological sciences literacy sessions were advised to search primary sources such as the United States and Canadian Patent Offices whenever possible as these databases provide a variety of search capabilities including the ability to conduct retrospective, classification and field searching. Using these primary sources also leads more directly to the complete texts of a patent, and any corresponding images. Searching proprietary databases that include patents may provide a convenient entry point for librarians wanting to introduce students to the patent literature, but students will develop a richer appreciation for the scientific literature by searching patent databases directly. 
Most developed countries now provide free access via the Internet to patents filed with their respective patent offices. The United States still receives the largest number of patent filings worldwide as most patent assignees outside of the U.S., i.e. Canada, tend to file with in the U. S. to ensure that their invention is protected in the world's largest economy (Kehoe and Yu, 2001), so if you have time to show only one patent database, the USPTO will generally provide the greatest depth and breadth of information. The size, searchability and well-developed tools such as the classification system, make the USPTO the most useful place to introduce North American students to patents and it is thus the focus of both the Biochemistry 561 class and this article.

\section{Biochemistry $561-A$ case study on searching patents}

Patent searching has been included in several library instruction sessions for students in four microbiology and biochemistry classes at the University of Calgary, but it was first introduced to students in BCEM561 (Biochemistry 561) in 2003. Biochemistry 561 is an advanced biochemistry class offered by the University of Calgary's Department of Biological Sciences. In addition to a midterm examination worth $40 \%$ of the overall course grade, students in this class are also required to complete a paper and an oral seminar worth $30 \%$ each. Students must conduct extensive literature reviews for both assignments. A total of 43 students have participated in this class over the past two years and have spent one of their weekly two-hour labs in a library instruction session where they receive a hands-on review of biological science databases and an introduction to patent searching using a web-based tutorial. One of the benefits of introducing students to patents in Biochemistry561 is that they have had at least one library instruction session where they have been introduced to traditional scientific literature and received hands-on instruction on using scientific databases. Most of these students have experience using Biological Abstracts, PubMed/Medline and Web of Science so much of the session can be devoted to more advanced searching techniques and the place of patents in the scientific literature. Also, this session is offered in the second or third week of classes so that students were able to apply the skills they have acquired in the library instruction session for their term papers and oral seminar reports. The web-based tutorial developed for the session is available to students throughout the semester through the course Blackboard page and the library subject pages.

While the ultimate goal of this session was to enhance students overall scientific literacy skills, the specific session objectives included the following:

- select and refine research topics

- develop effective search strategies

- select and search in databases appropriate to their information needs

With regard to patents, students should be able to:

- determine the purpose of a patent

- understand the data contained within a patent 
- relate the information contained within the patent to their assignment topic and the scientific literature as whole

- cite their sources, including patents, using an approved style guide

Students came to the library instruction session with topics they had been approved by their instructor, covering diverse aspects of biotechnology such as PCR (Polymerase Chain Reaction), cloning, microarrays, genomics, genetically modified organisms, drug and vaccine delivery, nanotechnology, and microbial engineering (See Appendix C). The librarian began by reviewing the session goals and providing an overview of the nature of scientific publishing. Students then had a brief review of advanced search strategies and time to practice searches with their topics on Biological Abstracts, PubMed, Web of Science, and SciFinder Scholar. Students compared search results from each database and received feedback from the librarian on their search results and discussed the similarities and differences of the results found in each database. The patent section of the session began with a discussion of the place of patents within scholarly literature, emphasizing that patent information is often not published in "traditional" scientific sources such as journals and that many recent scientific discoveries, especially in the field of biotechnology, can only be found in patents or patent applications. This was underlined with a sample search of patents using the instructor's name. The role of patents as a link between academic research and practical application was also noted.

Students were then introduced to both the Canadian Patent Office and United States Patent and Trademark Office (USPTO) databases and shown both introductory and advanced searching techniques. The first demonstration of the USPTO database used the "Quick Search" function with keywords chosen from the students' topics. Students were shown the fields that they could use to limit their searches, such as such as "Title", "Abstract", and "References", and these were related to their prior experience with the journal databases. The demonstration restricted the search to the abstract field to obtain more relevant results. One of the patents retrieved became the basis for a discussion on the key patent data fields and the types of information students might find in each field or section. Reviewing the initial results led to the generation of other keywords and also to a determination of relevant patent classification numbers. Students were briefly introduced to the patent classification system, and the necessity of using the class numbers to overcome the lack of controlled vocabulary subject headings, particularly for describing new inventions. Another rationale for discussing class and subclass numbers is that unlike journal articles, patent titles and abstracts are often deliberately ambiguous and not always indicative of the patent content. In order to narrow a search and retrieve more relevant results, students were shown how to identify a patent's priority class and subclass number (the number(s) listed and highlighted in the "Current U.S Class" section on the patent's first page). For example, the search shown to the students using the keywords "Drug Delivery" and limited to the abstract field produced 1400 patents. This number was reduced by limiting the search with other keywords such as "vaccine" or "controlled release". Students were then shown how to identify the Priority Class and Subclass numbers for selected patents and how this classification information could be used like subject descriptors or other controlled vocabulary terms to improve search precision. 
Finally students were shown how to search the USPTO Patent Applications database for even more current information. Students were reminded that while patents may take up to 25 months to be issued or granted (Office of Management and Budget, 2004), the turnaround time on patent applications was much faster and several students located several relevant patent applications that were issued only days prior to the library instruction session.

\subsection{Student feedback}

As the inclusion of patent searching in information literacy workshops is still quite new, students are routinely asked for feedback on the content and delivery of the workshops. Most of the students in Biochemistry 561 students had participated in a first-year library literacy session and in some cases a second-year session so were familiar with the basic search features in Biological Abstracts, Web of Science and PubMed. However, students had little or no previous familiarity with patent information.

Student comments and feedback were collected anonymously via a web-based assessment tool linked to the web-based tutorial. Most students commented that they had been unaware of the inherent complexity of many of the databases that they had used in the session and were surprised by the wealth of relevant and current information available from all patent providers, particularly the United States Patent and Trademark Office (USPTO). Almost all students found relevant patents or patent applications and indicated that they would be able to use the background information contained within the patents they had selected as starting point for some of their papers and oral presentations, or to supplement the information they had found in the journal literature. In addition, some students conducted a "Cited Reference Search" in Web of Science to track the research history of several inventors they had found in the patents, successfully integrating newly acquired skills with their knowledge of bibliographic databases. Students also commented during and after the session that they were impressed with the "real life" transferability that they had uncovered particularly those students researching "drug delivery devices", "genetically modified organisms" and "viruses". These students had found practical solutions for some of the questions they were researching and were better able to visualize how these discoveries actually worked by examining the available images.

Students noted the uniqueness of the patent information and the fact that they had found so little of this information in their searches of the journal literature. In other words, while there was considerable overlap and duplication among the results found in various bibliographic databases, there was comparatively little overlap between bibliographic databases and patent databases.

\section{Lessons learned}

1. Collaboration with faculty is key - similar sessions for other biochemistry and microbiology classes have been offered as instructors recognize the value of introducing 
students to patents within the context of other scientific literature sources. Encourage the class instructor to participate in a discussion with his/her views and uses of the patent literature.

2. Introduce patent searching only if references to the patent literature will be rewarded in subsequent assignments. Students should feel confident that patent searching will be an immediately beneficial skill as well as something they'll need to know for future careers, and many students in the sciences may have been encouraged to use only refereed journals in their research projects.

3. Instruction sessions should be offered early in the term so that students are able to transfer the skills they have acquired to their written and oral assignments.

4. Demonstrate first-nothing convinces students of the usefulness of patents faster than a list of spot-on-topic resources.

5. Clarify what students know about patents and clear up misconceptions-acknowledge that patents are not always easy to understand.

6. Preload a full patent-sometimes searching the USPTO means dealing with slow response times and loading the large patent documents can take some time.

7. Patents present opportunities and challenges for Instruction Librarians; they are rich sources of information but require more effort to learn and interpret.

\section{Conclusion}

Introducing patent literature to upper-level science students has enhanced their information literacy skills. Students participating in these sessions have a greater understanding of the different types of primary information in their subject areas and the place patents have in their field of study. These students are also more aware of the economic, legal and social issues surrounding the use of information or technologies and the importance of staying abreast of developments in their field of study.

Factors that contribute to the successful inclusion of patent information in library instruction sessions are those that constitute more general best practices. Collaboration with instructors is key to underlining the benefits of patent searching through descriptions of their own experiences as professionals and in explicit assignment criteria. This integration with course objectives and professional requirements increases the value students place on the skill and their likelihood of practicing and retaining it. The librarian is able to provide expert guidance to students entering a new and confusing information environment. By focusing on 'new' patent sources, the librarian was able to re-engage students with the research process, and the comparison of patent searching to bibliographic database searching also provided a useful review of skills and sources students had some familiarity with.

To maintain a central role in enhancing the information literacy of students in the sciences, science librarians need to become more fluent with myriad non-traditional sources such as patents, standards, genomic and bioinformatics databases. It is no longer sufficient to be expert in bibliographic research, as the information needs of students and faculty are 
changing rapidly, commensurate with the explosive growth in both raw data and processed information.

As introductory sessions in information literacy become standard in postsecondary education, it is imperative that we also develop advanced sessions for upper level students that take them deeper into the key information sources for their disciplines. Patent searching is just one such advanced topic, and now that the technological challenges in searching and retrieving patent information have been answered by the World Wide Web, librarians can easily introduce these rich resources to students.

On a very pragmatic level the development of instruction sessions that go beyond traditional bibliographic resources provides a welcome change from basic instruction, an opportunity to explore and understand information in a different format than most of us are used to. Since the introduction of patent searching in Biochemistry 561, more biological sciences instructors have requested the inclusion of patent databases in advanced courses. The novelty and perceived complexity of patents have prompted faculty who were confident enough in their students' research skills that they had not requested library instruction sessions to set up new course-integrated workshops. For the library, including patents in information literacy offerings has prompted the development of new skills in the librarians, new classes in information literacy and new collaborations with faculty. The students, however, are the ones who benefit most from the incorporation of this rich resource into their research skills.

\section{Appendix A. Key Patent Data Fields USPTO (United States Patent and Trademark Office)}

\section{Patent Number}

What is it?

Why is it important?

Patent Title

What is it?

Why is important?

The name given to an invention by the inventor.

Provides a basic description of the invention. Can be ambiguous and may not always be the most effective field to search for topic keywords.

Abstract

What is it?

Why is it important?

A brief summary of the patented invention.

The abstract contains many of the keywords that describe a patent. Unlike journal or conference abstracts, patent abstracts may not always fully describe key information about the patent.

Inventor

What is it? Why is important?
The name(s) of the person(s) credited with the invention.

US patents are usually assigned to individuals who may be assignors for their companies (the assignees). Inventors may have published similar journal articles on the same topic. 
US Classification

What is it? The original and cross-referenced classes by which the patent has been classified, based on the most recent US Manual of Classification.

Why is it important? Like database descriptors and subject headings, class searching will usually retrieve more precise and relevant results.

Claims

What is it?

The text of the patent claims.

Why is it important? The claims describe the scope of the invention and why it is patentable.

Other References

What is it? Bibliography of cited references such as books, journals and other patents.

Why is it important? Can be used to locate other references related to the search topic.

Description

What is it? A detailed description and summary of the invention

Why is it important? Provides a comprehensive overview of a topic.

\section{Appendix B. Locating Patent Information}

\section{Free Patent Sites}

Canadian Patent Office Database

United States Patent and Trademark Office

European Patent Office

Scirus

Free Patents Online

Pat2pdf.org

http://patents1.ic.gc.ca/intro-e.html

http://www.uspto.gov/

http://ep.espacenet.com/

http://www.scirus.com/srsapp/advanced/index.jsp

http://www.freepatentsonline.com/

http://www.pat2pdf.org/

Proprietary Patent Sites

Derwent World Patent Index

Delphion

http://thomsonderwent.com/products/patentresearch/dwpi/

Questel Orbit

http://www.delphion.com/

SciFinder Scholar (Chemical Abstracts)

http://www.questel.orbit.com/index.htm

Lexis-Nexis

http://www.cas.org/SCIFINDER/SCHOLAR/

http://www.lexisnexis.com/patentservices/

\section{Appendix C. Sample Searches (Biochemistry 561)}

\begin{tabular}{ll}
\hline Patent Number & Topic (Drug Delivery) \\
\hline $6,902,544$ & Troubleshooting accelerator system for implantable drug delivery pumps \\
$6,899,890$ & Bioadhesive drug delivery system \\
$6,896,659$ & Method for ultrasound triggered drug delivery using hollow microbubbles with controlled fragility \\
\hline
\end{tabular}


Appendix C (continued)

\begin{tabular}{|c|c|}
\hline $\begin{array}{l}6,895,271 \\
6,890,901\end{array}$ & $\begin{array}{l}\text { Iontophoretic drug delivery electrodes and method } \\
\text { Hyaluronic drug delivery system }\end{array}$ \\
\hline Patent Number & Topic (Transgenic Plants) \\
\hline $6,852,319$ & Method of use of transgenic plant expressed antibodies \\
\hline $6,812,338$ & $\begin{array}{l}\text { Peroxisomal ascorbate peroxidase gene induced by high temperature stress and a transgenic plant } \\
\text { exhibiting thermotolerance }\end{array}$ \\
\hline $6,610,544$ & $\begin{array}{l}\text { Regeneration of both plant tissues and transgenic plant tissues using a new plant hormone, 5- } \\
\text { bromoindole-3-acetic acid }\end{array}$ \\
\hline $6,596,929$ & $\begin{array}{l}\text { Element inducible in response to injury, a promoter inducible in response to injury and a } \\
\text { transgenic plant }\end{array}$ \\
\hline $6,576,820$ & Transgenic plant expressing soybean glycinin \\
\hline Patent Number & Topic (Gene Therapy) \\
\hline $6,902,907$ & Cystic fibrosis gene \\
\hline $6,900,038$ & eNOS mutations useful for gene therapy and therapeutic screening \\
\hline $6,899,871$ & Gene delivery system and methods of use \\
\hline $6,893,664$ & Particle delivery techniques \\
\hline $6,890,733$ & MEKK1 (serine threonine kinases)-interacting FHA (forkhead associated domain) protein 1 (M1F1) \\
\hline
\end{tabular}

\section{References}

Bowden, T. S., \& DiBenedetto, A. (2001). Information literacy in a biology laboratory session: An example of librarian-faculty collaboration. Research Strategies, 18, 143-149.

Brown, C. (2005). Where do molecular biology graduate students find information? Science \& Technology Libraries, 25(3), 89-104.

Chiang, C. S. (2004). Biology databases for the new life sciences. Science \& Technology Libraries, 25(1), 139-170.

Church, G.S., Carpenter, B.B. (2000, Fall). The life in inventions: Patents as sources of biological information. Issues in Science and Technology Librarianship, 28. Retrieved April 21, 2005, from http://www.istl.org/00fall/article5.html

Crespi, R. S. (2004). Patenting for the research scientist: An update. Trends in Biotechnology, 22(12), 638-642.

Glanzel, W., \& Meyer, M. (2003). Patents cited in the scientific literature: An exploratory study of 'reverse' citation relations. Scientometrics, 58(2), 415-428.

Kawakami, A.K. (1998, Summer). Patents and patent searching. Issues in Science and Technology Librarianship, 19. Retrieved April 19, 2005 from http://www.istl.org/98-summer/article5.html

Kehoe, C. A., \& Yu, X. J. (2001). Patent data for technology assessment, part I: Applications, patent databases, and retrieval systems. Science \& Technology Libraries, 22(1), 101-116.

Kehoe, C. A., \& Yu, X. J. (2001). Patent data for technology assessment, part II: Using U.S. patent data to examine trends in GPS technology. Science \& Technology Libraries, 22(1), 117-135.

McGill University Office of Technology Transfer (2005). Patents: What is a patent? Retrieved May 5, 2005, from http://www.mcgill.ca/ott/faqs/patents/

Mogee, M. E. (1997). Patents and technology intelligence. In W. B. Ashton, \& R. A. Klavans (Eds.), Technical intelligence for business: Keeping abreast of science and technology. Washington DC: Battelle Press. 
Office of Management and Budget. (2004). Performance and Management Assessment, United States Patent and Trademark Office. Budget of the U.S. Government, fiscal year 2004. Retrieved October 22, 2005, from http:/ www.whitehouse.gov/omb/budget/fy2004/pma/patents.pdf

World Intellectual Property Organization. (2002). Using Patent Information for the benefit of your SME. Retrieved May 3, 2005, from http://www.wipo.int/sme/en/ip-business/patents/patent-information.htm 